\title{
Use of Immunomodulating Drugs and Risk of Cutaneous Melanoma: A Nationwide Nested Case-Control Study
}

This article was published in the following Dove Press journal: Clinical Epidemiology

\section{Leon Alexander Mclaren \\ Berge iD ${ }^{\mathrm{I}-3}$ \\ Bettina Kulle Andreassen ' \\ Jo Steinson Stenehjem (D) 1,2,4 \\ Trond Heir (iD) 5,6 \\ Øystein Karlstad (iD) ${ }^{7}$ \\ Asta Juzeniene iD $^{8}$ \\ Reza Ghiasvand 1,9 \\ Inger Kristin Larsen (D) ${ }^{10}$ \\ Adele C Green (D) 11,12 \\ Marit Bragelien Veierød (iD ${ }^{2}$ \\ Trude Eid Robsahm (D) 1,3 \\ 'Department of Research, Cancer Registry of Norway, Oslo, Norway; ${ }^{2}$ Oslo Centre for Biostatistics and Epidemiology, Department of Biostatistics, Institute of Basic Medical Sciences, University of Oslo, Oslo, Norway; ${ }^{3}$ Institute for Cancer Research, Oslo University Hospital, Oslo, Norway; ${ }^{4}$ Division of Emergencies and Critical Care, Oslo University Hospital, Oslo, Norway; ${ }^{5}$ Institute of Clinical Medicine, Faculty of Medicine, University of Oslo, Oslo, Norway; ${ }^{6}$ Oslo Ischemia Study, Oslo University Hospital, Oslo, Norway; \\ ${ }^{7}$ Department of Chronic Diseases and Ageing, Norwegian Institute of Public Health, Oslo, Norway; ${ }^{8}$ Department of Radiation Biology, Institute for Cancer Research, Oslo University Hospital, Oslo, Norway; ${ }^{9}$ Oslo Centre for Biostatistics and Epidemiology, Oslo University Hospital, Oslo, Norway; ${ }^{10}$ Department of Registration, Cancer Registry of Norway, Oslo, Norway; "'Population Health Department, QIMR Berghofer Medical Research Institute, Brisbane, Australia; ${ }^{2}$ Molecular Oncology Unit, CRUK Manchester Institute, University of Manchester, Manchester, UK}

Correspondence: Leon Alexander Mclaren Berge

Cancer Registry of Norway, Majorstuen,

Oslo N-0304, Norway

Tel +4799605034

Email Leon.Berge@kreftregisteret.no
Purpose: Cutaneous melanoma is among the fastest growing malignancies in Norway and ultraviolet radiation (UVR) exposure is the primary environmental risk factor. Immunomodulating drugs can increase skin photosensitivity and suppress immune responses, and by such mechanisms influence melanoma risk. We, therefore, aimed to examine the associations between use of immunomodulating drugs and melanoma risk, at a nationwide population level.

Patients and Methods: In the Cancer Registry of Norway, we identified all cases aged $18-85$ with a first primary cutaneous melanoma diagnosed in 2007-2015 $(n=12,106)$. These were matched to population controls from the Norwegian National Registry 1:10 $(\mathrm{n}=118,564)$, on sex and year of birth using risk set sampling. Information on prescribed drugs (2004-2015) was obtained by linkage to the Norwegian Prescription Database (NorPD). Conditional logistic regression was used to estimate rate ratios (RRs) and 95\% confidence intervals (CIs) for associations between use of immunomodulating drugs (immunosuppressants and corticosteroids) and melanoma risk, adjusted for ambient UVR and other drug use.

Results: Compared with $\leq 1$ prescription, use of $\geq 8$ prescriptions of immunosuppressants was associated with increased risk of melanoma (RR 1.50, 95\% CI 1.27, 1.77). Similar associations were found for subgroups of immunosuppressants: drugs typically prescribed to organ transplant recipients (OTRs) (RR 2.02, 95\% CI 1.35, 3.03) and methotrexate (RR 1.27, 95\% CI $1.04,1.55)$. Similar results were found for high levels of cumulative doses and across all histological subtypes. Use of corticosteroids was not associated with melanoma risk.

Conclusion: We found a positive association between use of immunosuppressants and melanoma risk, with the highest risk seen for drugs prescribed to OTRs. Knowledge about this risk increase is important for physicians and users of these drugs, for intensified surveillance, awareness and cautious sun exposure.

Keywords: immunosuppressants, corticosteroids, melanoma, prescription drugs, pharmacoepidemiology, registry-based

\section{Summary}

The number of melanoma cases has reached historically high levels in fair-skinned populations worldwide, and is most likely caused by excessive sun exposure. However, immunomodulating drugs may influence the risk of melanoma by affecting our immune system's tumor surveillance or increasing the skin's sensitivity to sunlight. Such drugs include both immunosuppressants and systemic corticosteroids, typically prescribed to treat long-term autoimmune diseases and to prevent organ transplant 
rejection. As far as we know, this is the first epidemiological study that examines the association between use of immunomodulating drugs (including immunosuppressants and systemic corticosteroids) given for any indication, and melanoma risk on a nationwide level.

Compared with non-use, users of immunosuppressive drugs had an increased risk of melanoma, with the highest risk seen for drugs designed to prevent organ transplant rejection. Use of corticosteroids was not associated with melanoma risk. The side effects of immunosuppressive drugs, including immune suppression and increased photosensitivity in the skin, are possible explanations for these results. The findings could be valuable for both physicians and users of these drugs, as they could help reduce melanoma risk by increasing surveillance and awareness, which could lead to more careful sun exposure behavior.

\section{Introduction}

Cutaneous melanoma (hereafter melanoma) is the skin cancer that causes the highest number of deaths. It is the malignancy with the most rapid growth rate in Norway, which ranks among the top 3 countries worldwide, both in terms of incidence and mortality. ${ }^{1,2}$ The primary environmental risk factor for melanoma is ultraviolet radiation (UVR) exposure, which is estimated to be responsible for as much as three-quarters of all cases worldwide. ${ }^{3}$ The development of melanoma, however, is a process dependent on many factors in which individual susceptibility (number of nevi and skin sensitivity to $\mathrm{UVR}^{4}$ ), previous melanoma diagnosis, ${ }^{5}$ family history of melanoma, ${ }^{6}$ and additional factors such as anthropometric measures, ${ }^{7}$ hormonal factors ${ }^{8,9}$ and alcohol consumption ${ }^{10}$ are suggested to influence the risk.

Immunomodulating drugs comprise immunosuppressants and systemic corticosteroid hormones (hereafter corticosteroids), and are typically used for the treatment of inflammatory and autoimmune diseases, as well as to prevent the rejection of transplanted organs. ${ }^{11,12}$ The immunosuppressive actions of these drugs have a well-documented list of side-effects and toxicities due to the non-specific nature of immunesuppression. ${ }^{13,14}$ It is well-established that the immune system has an important role in the progression and regression of melanoma, and therefore it is likely that the development of this cancer is affected by long-term exposure to immunomodulating drugs. ${ }^{15}$ Organ transplant recipients (OTRs) are shown to experience an increased risk of melanoma, ${ }^{16-19}$ though such a relationship is not clear for other patient groups who use immunosuppressant drugs. ${ }^{20}$ Methotrexate is a commonly prescribed immunosuppressant, used to treat inflammatory and autoimmune disorders, such as rheumatoid arthritis and psoriasis. Studies indicate an association between methotrexate use and risk of melanoma and melanomaspecific mortality, ${ }^{21-23}$ although no dose-response association has been discovered. ${ }^{24}$ Other drugs with immunosuppressant actions, commonly used to treat these diseases, are also suggested to increase the melanoma risk. ${ }^{25-27}$ Furthermore, the propensity of certain immunosuppressants to exacerbate UVR-induced DNA damage is theorized to be responsible for a potential elevated risk of melanoma. ${ }^{28,29}$

Corticosteroids, and glucocorticoids in particular, are used as part of a variety of anti-inflammatory and immunosuppressive therapies, for conditions such as rheumatoid arthritis, inflammatory bowel syndrome, psoriasis, and eczema. $^{13}$ Epidemiological studies have shown that use of glucocorticoids is associated with increased risk of nonmelanoma skin cancers, ${ }^{30-32}$ and corticosteroids are found to increase the risk of cutaneous T-cell lymphoma. ${ }^{33}$ Epidemiological studies concerning a relationship with melanoma risk appear to be lacking. Pre-clinical studies, however, have demonstrated an ability by certain glucocorticoids (particularly dexamethasone) to inhibit human melanoma growth. ${ }^{34,35}$

To our knowledge, no nationwide epidemiological studies have investigated the associations between the prescribed use of immunosuppressants and corticosteroids, given for any indication, and melanoma risk. We aimed to investigate this association in a nested case-control study, employing population-based registries in Norway.

\section{Materials and Methods}

This case-control study was nested within the Norwegian National Registry, encompassing the entire adult Norwegian population during the period 2004-2015 (3.9 million people). A nested case-control design was chosen due to a principle of data minimization. Data were drawn from the Cancer Registry of Norway (CRN), the National Registry, the Norwegian Prescription Database (NorPD), and the Medical Birth Registry of Norway (Figure S1). Unique personal identification numbers (PIN) assigned to each person residing in Norway, were used to link the data across registries. Data collection procedures and study design features have been described. ${ }^{36}$

\section{Selection of Cases and Controls}

By law, the CRN has recorded data regarding cancer diagnoses since 1953. After 2000, $>99 \%$ of melanoma 
cases have been morphologically verified. ${ }^{1,37}$ We selected all first primary melanoma cases in the $\mathrm{CRN}$, which were diagnosed at the age of 18-85 in the period 2007-2015 $(n=12,106)$. The cases were recorded according to the International Classification of Diseases (ICD) of oncology 3rd edition (ICD-O-3), and the ICD 10th Revision (C43). Tumor site was categorized as head/neck (C43.0-4), trunk (C43.5), upper limb (C43.6), lower limb (C43.7), other (C43.8) and unspecified (C43.9). The histological subtype of each tumor (recorded according to ICD-O-3) was categorized as superficial spreading melanoma (SSM; 87433), nodular melanoma (NM; 87213) or other subtypes (87423, $87443,87453 / 87803 / 87613$, and 87203 (unspecified)). The $\mathrm{CRN}$ records the stage of melanoma at diagnosis based on clinical and pathological information on metastasis, which is the basis for its categorization as local disease (no metastases), regional metastasis (regional lymph nodes, satellites and in transit metastases), distant metastasis (non-regional lymph node and organ metastases) and unspecified.

For each melanoma case, 10 controls were drawn at random (with replacements) from the National Registry using risk set sampling, matched on sex and year of birth $(n=118,564)$. The controls in question had to be alive, free of any previous cancer diagnosis, and had to reside in Norway at their index date (date of diagnosis for respective case). This meant, however, that they could develop cancer afterwards. Permission to conduct the study was granted by the Norwegian Data Inspectorate, the Regional Committee for Medical and Health Research Ethics and each of the relevant registries.

\section{Assessment of Immunomodulating Drug Use}

All prescription drugs dispensed from Norwegian pharmacies have been recorded by the NorPD since 1 January 2004, except for those prescribed to institutionalized individuals. ${ }^{38}$ Drugs are classified according to the Anatomical Therapeutic Chemical (ATC) classification system version 2017..$^{38}$ Information about the date, prescriber, patient and drug is included for each record of dispensation. ${ }^{37}$ Information was obtained for the period 2004-2015, including the date of dispensing, ATC classification code, and the number of defined daily doses (DDD) dispensed, which is defined as the assumed average maintenance dose per day for a drug used for its main indication in adults. ${ }^{39}$ Immunosuppressants were defined as any drug included in the ATC group L04. ${ }^{40}$
Due to the elevated risk of skin cancer reported for OTRs and because the most commonly prescribed immunosuppressant was methotrexate (L04AX03) (11.5\%), immunosuppressant drugs commonly used by OTRs (L04AA06/10/18, L04AD01/02) and methotrexate (L04AX03) constituted two separate groups for analysis. Users of all remaining immunosuppressants constituted the category "Other drugs with immunosuppressant actions" (selective immunosuppressants (ATC codes L04AA13/21/24/27/31), tumor necrosis factor alpha inhibitors (ATC codes L04AB01/02/04/05/ 06), interleukin inhibitors (ATC codes L04AC03/05), and other immunosuppressive drugs (ATC codes L04AX01/02/ 05)). ${ }^{40}$ Corticosteroids were defined as any drug included in the ATC group H02, and were analyzed as one group due to the many different and overlapping indications for use. The most commonly prescribed type of corticosteroid, however, was glucocorticoids $(99.2 \%)$.

We quantified the number of prescriptions for each person based on their total number of filled prescriptions over the period 2004-2015. Exclusive use of immunosuppressants or corticosteroids for each individual was categorized according to the number of filled prescriptions since 2004: $\leq 1$ prescription, $2-7$ prescriptions and $\geq 8$ prescriptions. ${ }^{41}$ This was based on the assumption that each immunomodulating drug prescription is equivalent to 3 months of use. For methotrexate, each prescription may last up to 6 months depending on dosing regimen, ${ }^{42}$ thus the use was categorized as $\leq 1$ prescription, 2-3 prescriptions and $\geq 4$ prescriptions. While repeated prescriptions indicate sustained use of a drug, a single prescription reflects non-use or very limited use due to reasons such as lack of effect, side-effects, non-compliance or insufficient follow-up within the time period of the study. We therefore chose to combine non-use and limited use in the same category. The prescriptions in question could have been filled at separate or the same dates.

Cumulative dose of overall immunosuppressants or corticosteroids was calculated based on the total number of DDDs filled for each person and was categorized as non-users $(0)$ and users (1-365; 366-1100; 1101-1800; 1801-2900; $\geq 2901)$. For subgroup analyses, immunosuppressants prescribed to OTRs, methotrexate and "Other drugs with immunosuppressant actions", DDD were categorized as $1-365 ; 366-1800 ; \geq 1801$. The DDD categorizations were formed based on the assumption that immunomodulating drugs are typically prescribed for long-lasting inflammatory and/or immunosuppressive indications. ${ }^{12,13}$ The user levels thus corresponded to $<1$, 
$1-3,4-5,6-8,>8$ years of use, though some of these levels were collapsed in subgroup analyses due to low numbers of drug users.

All prescriptions filled within a year prior to and after individual index dates (date of diagnosis for cases and respective controls) were disregarded to reduce potential impact of reverse causation.

\section{Covariates}

There are several drugs which could influence the risk of melanoma by affecting skin photosensitivity or the mechanisms of the immune system. ${ }^{4-46}$ Therefore, information about ever-use of cardiovascular drugs (yes/no), antidepressant drugs (yes/no), and whether $>1$ prescription was filled of any other prescription drug (yes/no) was drawn from the NorPD, for the period 2004-2015. We used the information about use of such drugs up to a year prior to individual index dates. ${ }^{45,47}$

Ambient UVR exposure decreases from southern to northern Norway. The level of ambient UVR exposure was categorized according to the region of residence for each person. This information was obtained from both the CRN (for cases) and the NorPD (for controls), ${ }^{48}$ and was categorized into a five-level covariate: southeast coast, southeast inland, southwestern Norway, central Norway and northern Norway. ${ }^{7}$ We also categorized this information into a three-level covariate with highest (eastern and southern Norway), medium (western and central Norway) and lowest (northern Norway) levels of UVR exposure. ${ }^{49}$ Persons (both cases and controls) that lacked information concerning region of residence were excluded (67 cases and 3257 controls).

Parity is suggested to influence melanoma risk through female sex hormones, ${ }^{50,51}$ or factors related to parity (socioeconomic status and sunbathing habits). ${ }^{50}$ Therefore, we obtained individual information on number of children (up until index date) for all women from the Medical Birth Registry, and categorized it as 0, 1-3 and $>3$ children.

\section{Statistical Analyses}

We used conditional logistic regression to investigate the association between the use of prescribed immunosuppressant and corticosteroid drugs, and melanoma risk, estimating rate ratios (RRs) with 95\% confidence intervals (CIs). ${ }^{52}$ All analyses were adjusted for sex, year of birth and index date by design, including residential ambient UVR exposure and other drug use. Immunosuppressant
(L04) and corticosteroid (H02) drug use were also mutually adjusted. Analyses of OTR drugs and methotrexate were adjusted for corticosteroid (H02) drug use, including use of non-OTR and non-methotrexate immunosuppressive drugs, respectively. The results from the multivariable analyses are presented without adjustment for parity (for women), since this covariate had a negligible effect on the effect estimates.

A likelihood ratio test was used to test for interactions, on the multiplicative scale, between the number of immunosuppressant and corticosteroid prescriptions, and age (at index date), sex, ambient UVR exposure level (three level variable) and parity (women only). RRs were also calculated for the associations between the number of prescriptions of immunosuppressants and corticosteroids, and stratified sex, age (at index date), and residential ambient UVR exposure. Lastly, we conducted stratified analyses for tumor site, histological subtype, and clinical stage at diagnosis, in which contrast tests for heterogeneity between effect estimates were performed. ${ }^{53}$

The statistical software package $\mathrm{R}$ (version 3.5.1) was used to conduct all statistical analyses. ${ }^{54}$ The significance level was set to $5 \%$, and all tests were two-sided.

\section{Results}

The study sample consisted of 130,670 individuals, including 5988 male and 6118 female cases of melanoma diagnosed in the period 2007-2015, and 58,309 male and 60,255 female population controls (Table 1). Most cases and controls were $\geq 50$ years at index date and resided in the southern and eastern regions of Norway. The majority of melanomas were located on the trunk (47\%). SSM was the most frequent histological subtype (55\%), and most tumors were diagnosed with no metastasis $(81 \%)$. Of the study population, $1.8 \%$ had filled at least 1 immunosuppressant prescription, of which $60.5 \%$ had $\geq 8$ prescriptions, and $9.4 \%$ were in the highest dose level. By contrast, $14.7 \%$ had filled at least 1 corticosteroid prescription, of which $16.8 \%$ had $\geq 8$ prescriptions and $0.6 \%$ were in the highest dose level. While not depicted in Table 1, people who had filled both immunosuppressant and corticosteroid prescriptions constituted $1.5 \%$ of all study participants, and $9.7 \%$ of all immunomodulating drug users.

A $50 \%$ increased risk of melanoma was found in individuals with $\geq 8$ prescriptions filled of any immunosuppressant drug, compared with $\leq 1$ prescription filled (Table 2). When investigating immunosuppressant drugs prescribed to OTRs, $\geq 8$ prescriptions was associated with 
Table I Characteristics of Cases and Controls in the Study Sample

\begin{tabular}{|c|c|c|}
\hline Characteristics & $\begin{array}{l}\text { Cases } \\
(n=12,106) \\
\text { No. }(\%)\end{array}$ & $\begin{array}{l}\text { Controls } \\
(n=1 \mid 8,564) \\
\text { No. }(\%)\end{array}$ \\
\hline \multicolumn{3}{|l|}{ Sex } \\
\hline Men & $5988(49.5)$ & $58,309(49.2)$ \\
\hline Women & $6118(50.5)$ & $60,255(50.8)$ \\
\hline \multicolumn{3}{|l|}{ Age at diagnosis/index date, years } \\
\hline$<50$ & $3163(26.1)$ & $30,348(25.6)$ \\
\hline $50-69$ & $5616(46.4)$ & $55,279(46.6)$ \\
\hline$\geq 70$ & $3327(27.5)$ & $32,937(27.8)$ \\
\hline \multicolumn{3}{|l|}{ Residential ambient $U V R^{\mathrm{a}}$ exposure } \\
\hline Lowest (northern Norway) & $717(5.9)$ & $11,906(10.0)$ \\
\hline Medium (central/western Norway) & $1725(14.3)$ & $19,445(16.4)$ \\
\hline Highest (southern/eastern Norway) & $9664(79.8)$ & $87,213(73.6)$ \\
\hline \multicolumn{3}{|l|}{ Parity (women only) } \\
\hline No children & $1864(30.5)$ & $18,994(31.5)$ \\
\hline I-3 children & $3895(63.7)$ & $36,942(61.3)$ \\
\hline$>3$ children & $359(5.8)$ & $4319(7.2)$ \\
\hline \multicolumn{3}{|l|}{ Tumor site } \\
\hline Head/neck & $1315(10.9)$ & - \\
\hline Trunk & $566 \mathrm{I}(46.8)$ & - \\
\hline Upper limb & $1559(12.9)$ & - \\
\hline Lower limb & $2869(23.7)$ & - \\
\hline Other & $52(0.4)$ & - \\
\hline Unspecified & $650(5.3)$ & - \\
\hline \multicolumn{3}{|l|}{ Histological subtype } \\
\hline Superficial spreading melanoma & $6656(55.0)$ & - \\
\hline Nodular melanoma & $2079(17.2)$ & - \\
\hline Other & $3371(27.8)$ & - \\
\hline \multicolumn{3}{|l|}{ Clinical stage } \\
\hline Local disease & $9833(81.2)$ & - \\
\hline Regional metastasis & $573(4.7)$ & - \\
\hline Distant metastasis & $635(5.2)$ & - \\
\hline Unspecified & $1065(8.8)$ & - \\
\hline \multicolumn{3}{|l|}{ Use of immunomodulating drugs ${ }^{b}$} \\
\hline \multicolumn{3}{|l|}{$\begin{array}{l}\text { Overall use by number of } \\
\text { prescriptions }\end{array}$} \\
\hline$\leq 1$ & $11,029(91.1)$ & $107,998(91.1)$ \\
\hline $2-7$ & $647(5.3)$ & $6791(5.7)$ \\
\hline$\geq 8$ & $430(3.6)$ & $3775(3.2)$ \\
\hline \multicolumn{3}{|l|}{$\begin{array}{l}\text { Use by number of prescriptions of } \\
\text { each drug type }\end{array}$} \\
\hline$\leq 1$ & II,029 (91.1) & $107,998(91.1)$ \\
\hline \multicolumn{3}{|l|}{ I. Immunosuppressants (L04) ${ }^{\mathrm{C}}$} \\
\hline $2-7$ & $14(0.1)$ & $190(0.1)$ \\
\hline$\geq 8$ & $40(0.3)$ & $343(0.3)$ \\
\hline
\end{tabular}

(Continued)
Table I (Continued).

\begin{tabular}{|c|c|c|}
\hline Characteristics & $\begin{array}{l}\text { Cases } \\
(n=12,106) \\
\text { No. }(\%)\end{array}$ & $\begin{array}{l}\text { Controls } \\
(n=\mid \text { | 8,564) } \\
\text { No. (\%) }\end{array}$ \\
\hline \multicolumn{3}{|l|}{ II. Corticosteroids $\left(\mathrm{H}_{02}\right)^{\mathrm{d}}$} \\
\hline $2-7$ & $612(5.0)$ & $6392(5.4)$ \\
\hline$\geq 8$ & $201(1.7)$ & $2123(1.8)$ \\
\hline \multicolumn{3}{|l|}{ Use by cumulative dose (DDD $\left.{ }^{\mathrm{e}}\right)$} \\
\hline 0 & $10,283(84.9)$ & $100,488(84.8)$ \\
\hline \multicolumn{3}{|l|}{ I. Immunosuppressants overall (L04) ${ }^{c}$} \\
\hline $\mathrm{I}-365$ & II (0.1) & $197(0.2)$ \\
\hline $366-1100$ & $23(0.2)$ & $189(0.2)$ \\
\hline $1101-1800$ & $13(0.1)$ & $89(0.1)$ \\
\hline$|80|-2900$ & $6(0.05)$ & $96(0.1)$ \\
\hline$\geq 2901$ & $6(0.05)$ & $39(0.0)$ \\
\hline \multicolumn{3}{|l|}{ II. Corticosteroids overall $(\mathrm{HO2})^{d}$} \\
\hline $\mathrm{I}-365$ & $1353(\mid 1.2)$ & I3,793 (II.6) \\
\hline $366-1100$ & $137(1.1)$ & $1580(1.3)$ \\
\hline $1101-1800$ & $43(0.4)$ & $342(0.3)$ \\
\hline$|80|-2900$ & $17(0.1)$ & $164(0.1)$ \\
\hline$\geq 2901$ & $4(0.05)$ & $69(0.0)$ \\
\hline \multicolumn{3}{|l|}{ Ever use of other drugs } \\
\hline Antidepressant drugs $(\mathrm{N} 06 \mathrm{~A})^{\mathrm{f}}$ & $1870(15.4)$ & $20,243(17.1)$ \\
\hline Cardiovascular drugs $(\mathrm{Cl}-10)^{g}$ & $5840(48.2)$ & $56,263(47.5)$ \\
\hline Other drugs ${ }^{\mathrm{h}}$ & $5450(45.0)$ & $52,964(44.7)$ \\
\hline
\end{tabular}

Notes: ${ }^{a}$ Ultraviolet radiation; b Does not show number of individuals dispensed both immunosuppressant and corticosteroid prescriptions (mixed use); ' Users of immunosuppressants only; 'Users of corticosteroids only; ${ }^{\mathrm{e}} \mathrm{Defined}$ daily dose; ${ }^{\mathrm{f}}$ Use of antidepressants, but not cardiovascular drugs; 'Use of cardiovascular drugs, but not antidepressants; 'Use of all other drugs other than antidepressant or cardiovascular drugs.

a two-fold increased risk of melanoma, compared with $\leq 1$ prescription. For methotrexate, $\geq 4$ prescriptions was associated with a $27 \%$ increased melanoma risk, compared with $\leq 1$ prescription. No associations were found for use of "Other drugs with immunosuppressant actions" or corticosteroids (Table 2). When analyzing the use of immunosuppressants overall by cumulative dose in DDDs, significantly elevated RRs were found for all DDD categories $\geq 366$ (except 1801-2900), compared with 1-365 (Table 3). Analyses by drug group showed increased RRs by increasing DDD for OTR drugs in particular (RR 1.81, $95 \%$ CI $0.76,4.30$ ), but also for methotrexate (RR 1.47 , $95 \%$ CI $0.89,2.40$ ), although not statistically significant. No significant associations were found for cumulative doses of corticosteroids.

Compared with $\leq 1$ prescription, $\geq 8$ prescriptions of immunosuppressants was associated with increased risk 
Table 2 Rate Ratios (RRs) with 95\% Confidence Intervals (Cls) for Number of Prescriptions of Immunomodulating Drugs and Melanoma Risk

\begin{tabular}{|c|c|c|}
\hline Number of Prescriptions & No. Case/Controls & $\operatorname{RR}(95 \% \mathrm{Cl})^{\mathbf{a}}$ \\
\hline \multicolumn{3}{|l|}{$\begin{array}{l}\text { Immunosuppressants overall } \\
(\text { L04) })^{\mathrm{b}}\end{array}$} \\
\hline$\leq 1$ & $|\mathrm{I}, 858 / \mathrm{I}| 6,663$ & 1.00 (reference) \\
\hline $2-7$ & $63 / 637$ & $0.98(0.75,1.28)$ \\
\hline$\geq 8$ & $185 / 1264$ & $1.50(1.27,1.77)$ \\
\hline \multicolumn{3}{|l|}{ OTR $^{c}$ drugs (L04AA06/10/18, } \\
\hline \multicolumn{3}{|l|}{ LO4AD0 I/02) $^{\mathrm{d}}$} \\
\hline$\leq 1$ & $|2,069 /| \mid 8,363$ & 1.00 (reference) \\
\hline $2-7$ & $6 / 50$ & I.II $(0.47,2.6 \mathrm{I})$ \\
\hline$\geq 8$ & $31 / / 51$ & $2.02(1.35,3.03)$ \\
\hline \multicolumn{3}{|l|}{ Methotrexate $(\mathrm{L} 04 \mathrm{AX} 03)^{\mathrm{e}}$} \\
\hline$\leq 1$ & II,950/II 7,270 & 1.00 (reference) \\
\hline $2-3^{f}$ & $22 / 267$ & $0.79(0.5 \mathrm{I}, 1.22)$ \\
\hline$\geq 4^{f}$ & $134 / 1027$ & $1.27(1.04,1.55)$ \\
\hline \multicolumn{3}{|l|}{ Other drugs with } \\
\hline \multicolumn{3}{|l|}{ immunosuppressant actions } \\
\hline \multicolumn{3}{|l|}{ (L04AAI3/2I/24/27/3I, } \\
\hline \multicolumn{3}{|l|}{ L04AB0I/02/04/05/06, } \\
\hline \multicolumn{3}{|l|}{ L04AC03/05, L04AX0I/02/05) } \\
\hline$\leq 1$ & $|2,002 / 1| 7,736$ & 1.00 (reference) \\
\hline $2-7$ & $27 / 249$ & $1.00(0.66,1.50)$ \\
\hline$\geq 8$ & $77 / 579$ & I.19 (0.9I, I.54) \\
\hline \multicolumn{3}{|l|}{ Systemic corticosteroids } \\
\hline \multicolumn{3}{|l|}{$(\mathrm{H} 02)^{\mathrm{h}}$} \\
\hline$\leq 1$ & $|\mathrm{I}| ,0|/| 08,72 \mathrm{I}$ & I.00 (reference) \\
\hline $2-7$ & $691 / 6917$ & $0.96(0.88,1.04)$ \\
\hline$\geq 8$ & $314 / 2926$ & $0.98(0.86,1.11)$ \\
\hline
\end{tabular}

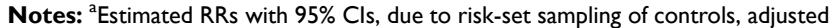
for sex and birth year (by design) and ever use of other drugs and residential ambient ultraviolet radiation exposure; ${ }^{b}$ Additionally adjusted for number of systemic corticosteroid prescriptions; 'Organ transplant recipient; ${ }^{\mathrm{d} A d d i t i o n a l l y}$ adjusted for number of non-organ transplant immunosuppressants and systemic corticosteroid prescriptions; ${ }^{\mathrm{e} A d d i t i o n a l l y ~ a d j u s t e d ~ f o r ~ n u m b e r ~ o f ~ n o n-~}$ methotrexate immunosuppressants and systemic corticosteroid prescriptions; 'Methotrexate prescription categories compensate for comparatively longer duration of use; ${ }^{8}$ Additionally adjusted for number of organ transplant and methotrexate immunosuppressant and systemic corticosteroid prescriptions; hAdditionally adjusted for number of immunosuppressant prescriptions.

of melanoma for both men and women $\left(\mathrm{P}_{\text {interaction }}=0.068\right)$ (Table 4). Increased risk was also found for age groups $>50$ years $\left(\mathrm{P}_{\text {interaction }}=0.174\right)$ and for residential regions with the highest and medium levels of ambient UVR exposure $\left(\mathrm{P}_{\text {interaction }}=0.105\right)$. There were negligible differences in the results of multivariable analyses between the five-level and three-level variable of residential ambient UVR exposure (not shown). Compared with $\leq 1$ prescription, $\geq 8$ prescriptions of corticosteroids was associated with a $20 \%$ reduced melanoma risk in men.
Table 3 Rate Ratios (RRs) with $95 \%$ Confidence Intervals (Cls) for Cumulative Defined Daily Dose (DDD) of Immunomodulating Prescription Drugs and Melanoma Risk

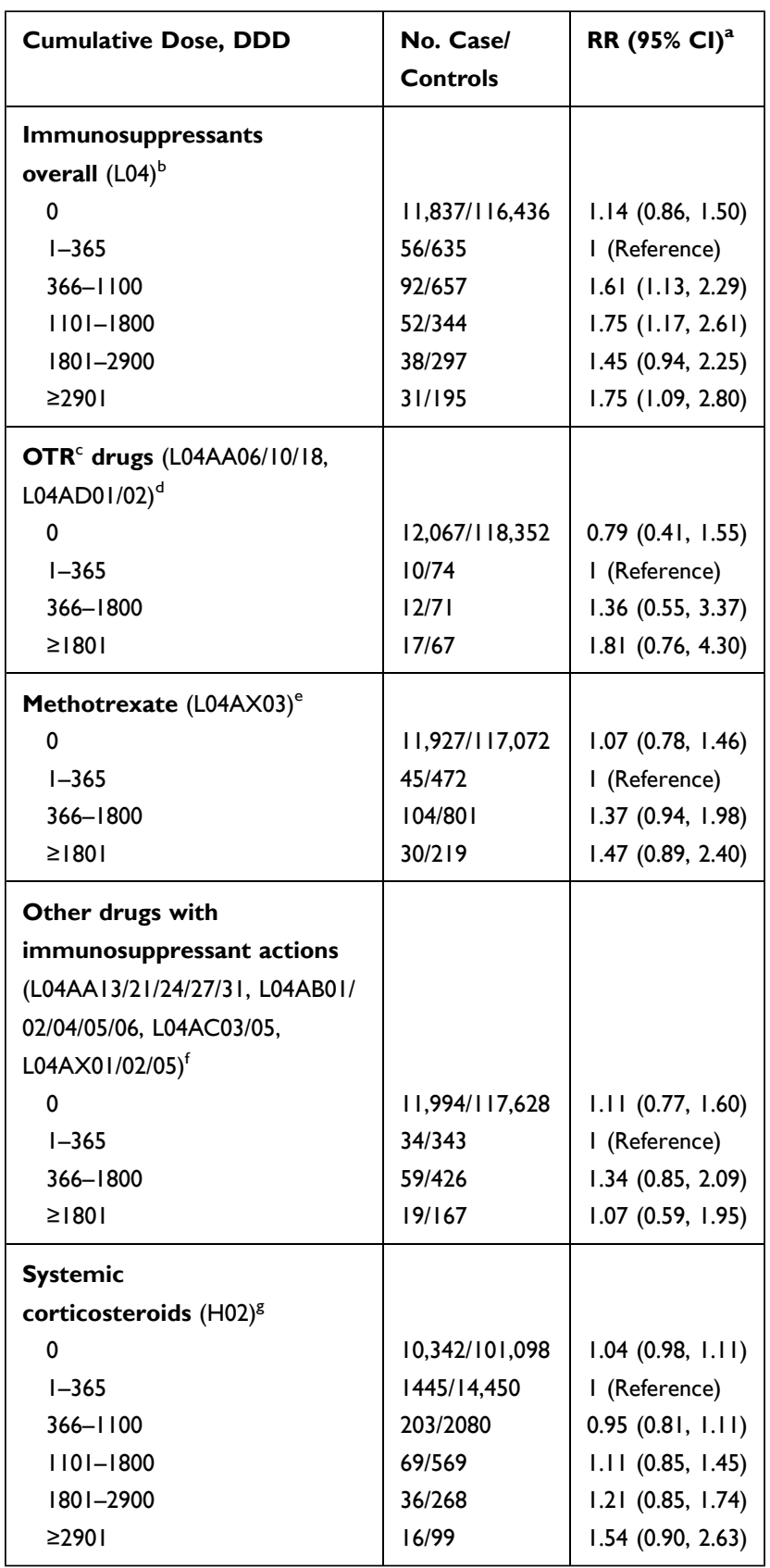

Notes: a Estimated RRs with $95 \% \mathrm{Cls}$, due to risk-set sampling of controls, adjusted for sex and birth year (by design) and ever use of other drugs and residential ambient ultraviolet radiation exposure; 'Additionally adjusted for cumulative corticosteroid dose; ${ }^{\mathrm{C}}$ Organ transplant recipient; ${ }^{\mathrm{d}}$ Additionally adjusted for cumulative dose of non-organ transplant immunosuppressants and systemic corticosteroids; ${ }^{\mathrm{e}}$ Additionally adjusted for cumulative dose of non-methotrexate immunosuppressants and systemic corticosteroids; 'Additionally adjusted for cumulative dose of organ transplant immunosuppressants, methotrexate and systemic corticosteroids; ${ }^{8}$ Additionally adjusted for cumulative dose of immunosuppressants.

Analyses stratified by residential region $\left(\mathrm{P}_{\text {interaction }}=\right.$ 0.064), showed that melanoma risk within the region of medium UVR exposure increased by number of 
Table 4 Rate Ratios (RRs) with 95\% Confidence Intervals (Cls) for Melanoma Risk for $2-7$ and $\geq 8$ vs $\leq 1$ Prescription of Immunosuppressants and Systemic Corticosteroids, Stratified by Sex, Age at Diagnosis/Index Date and Residential Ambient Ultraviolet Radiation (UVR) Exposure

\begin{tabular}{|c|c|c|}
\hline \multirow[t]{3}{*}{ Variables } & \multicolumn{2}{|c|}{ 2-7 and $\geq 8$ Prescriptions vs $\leq 1$ Prescription } \\
\hline & $\begin{array}{l}\text { Immunosuppressants } \\
\text { (L04) }\end{array}$ & $\begin{array}{l}\text { Systemic } \\
\text { Corticosteroids } \\
\text { (H02) }\end{array}$ \\
\hline & $\operatorname{RR}(95 \% \mathrm{Cl})^{\mathrm{a}}$ & $\operatorname{RR}(95 \% \mathrm{Cl})^{\mathrm{b}}$ \\
\hline \multicolumn{3}{|l|}{ Sex } \\
\hline \multicolumn{3}{|l|}{ Men } \\
\hline$\leq 1$ & 1.00 & 1.00 \\
\hline $2-7$ & $1.25(0.87,1.80)$ & $0.93(0.82,1.05)$ \\
\hline$\geq 8$ & $1.36(1.05,1.77)$ & $0.80(0.65,0.98)$ \\
\hline \multicolumn{3}{|l|}{ Women } \\
\hline$\leq 1$ & 1.00 & 1.00 \\
\hline $2-7$ & $0.79(0.54,1.16)$ & $0.98(0.88,1.09)$ \\
\hline$\geq 8$ & $1.60(1.29,1.98)$ & $1.12(0.95,1.3 \mathrm{I})$ \\
\hline$P_{\text {interaction }}{ }^{f}$ & 0.068 & 0.018 \\
\hline \multicolumn{3}{|c|}{ Age at diagnosis/index date ${ }^{d}$, years } \\
\hline \multicolumn{3}{|l|}{$<50$} \\
\hline$\leq 1$ & 1.00 & 1.00 \\
\hline $2-7$ & $0.89(0.46,1.72)$ & $1.04(0.86,1.24)$ \\
\hline$\geq 8$ & $1.16(0.74,1.82)$ & $1.15(0.77,1.73)$ \\
\hline \multicolumn{3}{|l|}{$50-69$} \\
\hline$\leq 1$ & 1.00 & 1.00 \\
\hline $2-7$ & $1.18(0.83,1.69)$ & $0.91(0.81,1.04)$ \\
\hline$\geq 8$ & $1.47(1.17,1.85)$ & $0.98(0.80,1.20)$ \\
\hline \multicolumn{3}{|l|}{$>70$} \\
\hline$\leq 1$ & 1.00 & 1.00 \\
\hline $2-7$ & $0.76(0.46,1.26)$ & $0.97(0.85,1.11)$ \\
\hline$\geq 8$ & $1.72(1.29,2.29)$ & $0.94(0.79,1.13)$ \\
\hline$P_{\text {interaction }}{ }^{f}$ & 0.174 & 0.405 \\
\hline \multicolumn{3}{|c|}{ Residential ambient UVR exposure ${ }^{e}$} \\
\hline \multicolumn{3}{|c|}{ Low (northern } \\
\hline \multicolumn{3}{|l|}{ Norway) } \\
\hline$\leq 1$ & 1.00 & 1.00 \\
\hline $2-7$ & $0.14(0.02,1.23)$ & $0.84(0.46,1.53)$ \\
\hline$\geq 8$ & $0.77(0.27,2.18)$ & $1.30(0.60,2.84)$ \\
\hline \multicolumn{3}{|c|}{$\begin{array}{l}\text { Medium (central/ } \\
\text { western Norway) }\end{array}$} \\
\hline$\leq 1$ & 1.00 & 1.00 \\
\hline $2-7$ & $1.14(0.44,2.90)$ & $0.90(0.68,1.19)$ \\
\hline$\geq 8$ & $2.36(1.26,4.45)$ & $0.47(0.27,0.8 \mathrm{I})$ \\
\hline \multicolumn{3}{|c|}{$\begin{array}{l}\text { Highest (southern/ } \\
\text { eastern Norway) }\end{array}$} \\
\hline$\leq 1$ & 1.00 & 1.00 \\
\hline
\end{tabular}

(Continued)
Table 4 (Continued).

\begin{tabular}{|c|c|c|}
\hline \multirow[t]{3}{*}{ Variables } & \multicolumn{2}{|c|}{ 2-7 and $\geq 8$ Prescriptions vs $\leq$ I Prescription } \\
\hline & $\begin{array}{l}\text { Immunosuppressants } \\
\text { (L04) }\end{array}$ & $\begin{array}{l}\text { Systemic } \\
\text { Corticosteroids } \\
\text { (H02) }\end{array}$ \\
\hline & $\operatorname{RR}(95 \% \mathrm{Cl})^{\mathrm{a}}$ & $\operatorname{RR}(95 \% \mathrm{Cl})^{\mathrm{b}}$ \\
\hline $2-7$ & $1.02(0.76,1.37)$ & $0.95(0.87,1.04)$ \\
\hline$\geq 8$ & $1.52(1.26,1.85)$ & $1.01(0.87,1.16)$ \\
\hline$P_{\text {interaction }}{ }^{f}$ & 0.105 & 0.064 \\
\hline
\end{tabular}

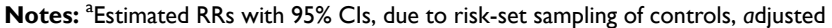

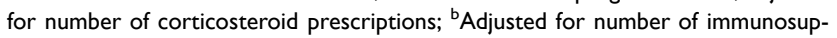
pressant prescriptions; 'Adjusted for age (by design), ever use of other drugs and residential ambient UVR exposure; 'Adjusted for sex (by design) ever use of other drugs and residential ambient UVR; ${ }^{\mathrm{A}}$ Adjusted for sex and age (by design) and ever use of other drugs; 'Interaction is analyzed on a multiplicative scale.

immunosuppressant drug prescriptions, while risk decreased by number of corticosteroid drug prescriptions. Melanoma risk also increased by number of immunosuppressant drug prescriptions within the region of highest UVR exposure, though no association was seen for corticosteroids.

Compared with $\leq 1$ prescription, $\geq 8$ prescriptions of immunosuppressants was associated with increased risk of melanoma located at the head/neck (RR 2.22, 95\% CI $1.45,3.40)$, trunk (RR 1.67, 95\% CI 1.30, 2.13) and upper limb (RR 1.51, 95\% CI 0.96, 2.36), though not significant for the latter (Table 5). Significantly elevated RRs were also found for $\geq 8$ prescriptions of immunosuppressants for all histological subtypes and for local disease and regional metastasis. No association between corticosteroids and melanoma were found across tumor site, histological subtype or clinical stage. Tests for heterogeneity found no difference between the effect estimates for tumor site, histological subtype or clinical stage, for either immunosuppressants $\left(\mathrm{P}_{\text {heterogeneity }}=\right.$ $0.112,0.676,0.338$, respectively) or corticosteroid prescriptions $\left(\mathrm{P}_{\text {heterogeneity }}=0.507,0.417,0.260\right.$, respectively) and melanoma (Table 5).

\section{Discussion}

In this population-based study, using data from nationwide health registries, we investigated associations between use of prescribed immunosuppressant and corticosteroid drugs, and melanoma risk. Users of immunosuppressant drugs had a higher risk of melanoma. This was found for both users of $\geq 8$ prescriptions and for increasing levels of 
Table 5 Rate Ratios (RRs) with 95\% Confidence Intervals (Cls) for 2-7 and $\geq 8$ vs $\leq$ I Prescription of Immunosuppressants and Systemic Corticosteroids, and Melanoma Risk, Stratified by Tumor Site, Histological Subtype, and Clinical Stage at Diagnosis

\begin{tabular}{|c|c|c|}
\hline & \multicolumn{2}{|c|}{ 2-7 and $\geq 8$ Prescriptions vs $\leq$ I Prescription } \\
\hline & $\begin{array}{l}\text { Immunosuppressants } \\
\text { (L04) }\end{array}$ & $\begin{array}{l}\text { Systemic } \\
\text { Corticosteroids } \\
(\mathrm{H} 02)\end{array}$ \\
\hline & $\operatorname{RR}(95 \% \mathrm{CI})^{\mathrm{a}}$ & $\operatorname{RR}(95 \% \mathrm{CI})^{\mathbf{b}}$ \\
\hline \multicolumn{3}{|l|}{ Tumor site (cases/controls) } \\
\hline \multicolumn{3}{|l|}{ Head/neck $(13|5 /| 2,842)$} \\
\hline$\leq 1$ & 1.00 & 1.00 \\
\hline $2-7$ & $1.71(0.90,3.22)$ & $0.98(0.78,1.24)$ \\
\hline$\geq 8$ & $2.22(1.45,3.40)$ & $1.17(0.87,1.57)$ \\
\hline \multicolumn{3}{|l|}{ Trunk $(5661 / 55,107)$} \\
\hline$\leq 1$ & 1.00 & 1.00 \\
\hline $2-7$ & $1.24(0.86,1.79)$ & $0.95(0.84,1.07)$ \\
\hline$\geq 8$ & $1.67(1.30,2.13)$ & $0.92(0.75,1.12)$ \\
\hline \multicolumn{3}{|l|}{ Upper limb $(1559 / 15,197)$} \\
\hline$\leq 1$ & 1.00 & 1.00 \\
\hline $2-7$ & $0.31(0.10,0.98)$ & $0.95(0.76,1.19)$ \\
\hline$\geq 8$ & $1.51(0.96,2.36)$ & $1.08(0.78,1.50)$ \\
\hline \multicolumn{3}{|l|}{ Lower limb $(2869 / 28,005)$} \\
\hline$\leq 1$ & 1.00 & 1.00 \\
\hline $2-7$ & $0.72(0.40,1.31)$ & $0.93(0.78,1.10)$ \\
\hline$\geq 8$ & $1.01(0.70,1.47)$ & $0.96(0.73,1.27)$ \\
\hline \multicolumn{3}{|l|}{ Other $(52 / 51 \mathrm{I})$} \\
\hline$\leq 1$ & 1.00 & 1.00 \\
\hline $2-7$ & $1.04 *-8(0, \mathrm{NA})$ & $1.04(0.29,3.68)$ \\
\hline$\geq 8$ & $2.27(0.21,25.09)$ & $0.37(0.04,3.00)$ \\
\hline \multicolumn{3}{|l|}{ Unspecified (650/6357) } \\
\hline$\leq 1$ & 1.00 & 1.00 \\
\hline $2-7$ & $0.96(0.29,3.21)$ & $1.08(0.77,1.51)$ \\
\hline$\geq 8$ & $1.04(0.43,2.49)$ & $0.68(0.36,1.28)$ \\
\hline$P_{\text {heterogeneity }}$ & 0.112 & 0.507 \\
\hline \multicolumn{3}{|c|}{ Histological subtype (cases/controls) } \\
\hline \multicolumn{3}{|l|}{$\operatorname{SSM}^{c}(6656 / 64,826)$} \\
\hline$\leq 1$ & 1.00 & 1.00 \\
\hline $2-7$ & $0.90(0.62,1.3 \mathrm{I})$ & $0.97(0.87,1.08)$ \\
\hline$\geq 8$ & $1.41(1.12,1.76)$ & $0.99(0.83,1.19)$ \\
\hline \multicolumn{3}{|l|}{$N^{d}(2079 / 20,330)$} \\
\hline$\leq 1$ & 1.00 & 1.00 \\
\hline $2-7$ & $1.02(0.56,1.87)$ & $0.92(0.75,1.12)$ \\
\hline$\geq 8$ & $1.56(1.06,2.31)$ & $1.10(0.83,1.45)$ \\
\hline \multicolumn{3}{|l|}{ Other $^{e}(337 I / 32,863)$} \\
\hline$\leq 1$ & 1.00 & 1.00 \\
\hline $2-7$ & I.II $(0.69,1.78)$ & $0.96(0.82,1.12)$ \\
\hline$\geq 8$ & $1.67(1.21,2.30)$ & $0.86(0.68,1.10)$ \\
\hline$P_{\text {heterogeneity }}$ & 0.676 & 0.417 \\
\hline
\end{tabular}

(Continued)
Table 5 (Continued).

\begin{tabular}{|c|c|c|}
\hline & \multicolumn{2}{|c|}{ 2-7 and $\geq 8$ Prescriptions vs $\leq 1$ Prescription } \\
\hline & $\begin{array}{l}\text { Immunosuppressants } \\
\text { (L04) }\end{array}$ & $\begin{array}{l}\text { Systemic } \\
\text { Corticosteroids } \\
(\mathrm{H} 02)\end{array}$ \\
\hline & $\operatorname{RR}(95 \% \mathrm{Cl})^{\mathbf{a}}$ & $\operatorname{RR}(95 \% \mathrm{Cl})^{\mathbf{b}}$ \\
\hline \multicolumn{3}{|c|}{ Clinical stage (cases/controls) } \\
\hline \multicolumn{3}{|c|}{$\begin{array}{l}\text { Local disease (9833/ } \\
95.842 \text { ) }\end{array}$} \\
\hline$\leq 1$ & 1.00 & 1.00 \\
\hline $2-7$ & $0.88(0.65,1.19)$ & $0.95(0.87,1.04)$ \\
\hline$\geq 8$ & $1.50(1.26,1.79)$ & $1.03(0.90,1.18)$ \\
\hline \multicolumn{3}{|c|}{ Regional metastasis (573/ } \\
\hline \multicolumn{3}{|l|}{$5610)$} \\
\hline$\leq 1$ & 1.00 & 1.00 \\
\hline $2-7$ & $0.94(0.28,3.12)$ & $0.92(0.64,1.33)$ \\
\hline$\geq 8$ & $2.17(1.04,4.54)$ & $0.73(0.4 \mathrm{I}, \mathrm{I} .3 \mathrm{I})$ \\
\hline \multicolumn{3}{|c|}{ Distant metastasis (635/ } \\
\hline \multicolumn{3}{|l|}{ 6216) } \\
\hline$\leq 1$ & 1.00 & 1.00 \\
\hline $2-7$ & $1.27(0.43,3.73)$ & $1.01(0.71,1.43)$ \\
\hline$\geq 8$ & $1.39(0.60,3.20)$ & $0.87(0.49,1.54)$ \\
\hline \multicolumn{3}{|c|}{ Unspecified (1065/ } \\
\hline \multicolumn{3}{|l|}{$10,351)$} \\
\hline$\leq 1$ & 1.00 & 1.00 \\
\hline $2-7$ & $1.99(0.95,4.15)$ & I.II $(0.8 \mathrm{I}, 1.54)$ \\
\hline$\geq 8$ & $0.48(0.12,2.03)$ & $0.58(0.30,1.13)$ \\
\hline$P_{\text {heterogeneity }}$ & 0.338 & 0.260 \\
\hline
\end{tabular}

Notes: a Estimated RRs with $95 \%$ Cls, due to risk-set sampling of controls, adjusted for sex and age (by design), number of corticosteroid prescriptions, ever use of other drugs, and residential ambient ultraviolet radiation exposure; ${ }^{\mathrm{b}} \mathrm{Adjusted} \mathrm{for}$ sex and age (by design), number of immunosuppressant prescriptions, ever use of other drugs, and residential ambient ultraviolet radiation exposure; 'Superficial spreading melanoma; ${ }^{\mathrm{D}}$ Nodular melanoma; ${ }^{\mathrm{e}}$ Includes all other histological types.

cumulative DDDs, with the highest risk observed for users of immunosuppressants prescribed for OTRs. Positive associations between melanoma risk and $\geq 8$ prescriptions of immunosuppressants were found for all histological subtypes. No associations were found for users of corticosteroids, apart from a decreased risk of melanoma in men and for users residing in the region with medium UVR exposure.

The results from pre-clinical studies concerning the association between immunosuppressants and melanoma indicate a prevailing growth inhibition of melanoma cells, primarily through pro-apoptotic mechanisms. ${ }^{55-57}$ Previous epidemiological studies concerning this association are primarily based on patient-cohorts, which overwhelmingly show significantly increased melanoma risk in OTRs, compared with 
non-OTRs. ${ }^{16-18,58}$ Immunosuppressants used by patient groups with conditions such as inflammatory bowel disease or psoriasis are also associated with increased melanoma risk, ${ }^{26}$ particularly the use of methotrexate. ${ }^{21,23,59,60}$

As opposed to cohorts of patients, this population-based register study examined the use of immunosuppressants among melanoma cases and their controls on a nationwide basis. Although we were able to separately examine the use of drugs commonly prescribed to OTRs and for methotrexate alone, we did not have sufficient power to analyze individual drugs, or indeed by ATC 4th levels. The increased melanoma risk found with use of immunosuppressant drugs prescribed to OTRs is in line with results from previous studies and supports long-term and/or high intensity drug use of this type as a risk factor for melanoma. For methotrexate use, melanoma risk increased for users of $\geq 8$ prescriptions, which is also in line with previous observations. ${ }^{21-23}$ However, no association with melanoma was found for "Other drugs with immunosuppressant actions", and we were not able to clarify the indeterminate findings in previous studies for these drugs. ${ }^{61-63}$

We found that use of immunosuppressants increased the risk of all histological subtypes of melanoma, which could be indicative of a common mechanism of effect. A lack of heterogeneity between these effect estimates underscores this. A significantly increased risk of melanoma was found for the head/neck and trunk locations. However, a lack of heterogeneity suggested that there was no difference between the effect estimates of each location. On the other hand, the head/neck is considered more chronically exposed to UVR, while exposure at the trunk is typically repeatedly intermittent. This might be indicative of an interaction between UVR radiation and immunosuppressants with photosensitizing potential. ${ }^{28}$ Moreover, the elevated melanoma risk in immunosuppressant users was found in regions with medium and the highest levels of ambient UVR exposure, which could support a photosensitizing effect of the drugs. ${ }^{48}$ However, low power and a lack of individual UVR exposure metrics may be the reason for not seeing a similar effect in the Northern region; this might have likewise prevented an interaction with region of residence. There were no sex-specific differences observed. The increased risk was found for users of immunosuppressants in age groups $>50$ years, though low power due to a small sample size may be why a similarly increased melanoma risk was not observed in users $<50$ years of age, or why an interaction with immunosuppressant drug use was not found.
We found no indication of a relation between melanoma risk and use of corticosteroids, although a reduced risk was seen in men and in the region with medium UVR exposure. Previous epidemiological studies reported that use of glucocorticoids in particular is associated with risk of other cutaneous malignancies, ${ }^{30-33}$ while this relationship seems not to be examined for melanoma. The prevailing consensus from pre-clinical studies, however, indicates an anti-proliferative effect of corticosteroids, through suppression of angiogenesis and growth of melanoma cells in vivo. ${ }^{34,35,64-66}$

A major strength of our study is that it is based on complete and high-quality registers with nationwide coverage and mandatory reporting, providing detailed information regarding melanoma diagnoses and pre-diagnostic drug use. The nature of the study precludes the influence of recall bias. An attempt to control for reverse causation bias was made by excluding prescriptions received in the last year before index date. The impact of primary non-adherence is limited by the fact that only information on drugs actually dispensed from pharmacies to patients is recorded in the NorPD, which is more indicative of use than databases including all drugs prescribed by physicians. ${ }^{67}$

The study also has weaknesses to consider while interpreting the results. We had no information concerning individual UVR exposure, such as behaviors related to recreational sun exposure, indoor tanning and sunburns, which might, apart from causing melanoma in their own right, interact with drugs with photosensitizing effects. For example, men who use glucocorticoids may be less exposed to sunlight and thus have a lower risk of melanoma, due to behavioral adaptations associated with an underlying disease. Regarding the increased melanoma risk for users of immunosuppressants, a reduction in outdoor activity among patients with conditions such as rheumatoid arthritis, would reduce rather than increase the risk estimates in our study. Additionally, a lack of power due to small sample sizes may have prevented the detection of significant interactions between number of prescriptions and certain covariates, hence the often wide CIs.

Immunosuppressant drug therapy often consists of several different drugs given together as part of a collective drug regimen. In addition, the number and combinations of these drugs may change over time. ${ }^{11,12,68}$ This makes it challenging to narrow the risk of disease down to the influence of one specific drug, as an increased risk of melanoma may be due to the cumulative effect of the entire immunosuppressive drug regimen. Patient characteristics such as 
indications for drug use could also be sources of residual confounding, as the risk of melanoma may be modified by the underlying conditions for which these drugs are prescribed, including autoimmune and inflammatory diseases. Moreover, $3 \%$ of controls were excluded due to lack of residential information, which was sourced by NorPD. Individuals who lacked this information would by definition consist of those who did not receive any prescription drugs. Thus, the exclusion may have introduced a certain degree of selection bias. They could, for example, represent exceptionally healthy people or long-term inpatients.

Furthermore, there were not enough users across the different drugs to properly differentiate and examine the type and severity of these wide-ranging indications. This may have introduced potential confounding by indication, especially when considering that autoimmune skin disorders (e.g. psoriasis) are treated with high-dose phototherapy which may increase the risk of melanoma. ${ }^{69}$ Different indications can also be related to other factors suggested to influence melanoma risk (e.g. obesity, socioeconomic factors, hormones and alcohol use). ${ }^{5-10}$ With an unknown latency time for melanoma, the follow-up time from start of drug exposure to index date may be insufficient to establish a true association.

Finally, as most people in Norway reside in the southern and eastern regions of the country, we cannot discount the possibility that intra-regional differences regarding prescription practices and access to healthcare have influenced the results. ${ }^{70}$ However, adjusting for other drug use could act as a proxy in this regard, and we have also adjusted for residential region.

\section{Conclusions}

To our knowledge, this is the first nationwide registerbased study examining the association between the use of immunomodulating drugs (immunosuppressants and corticosteroids), given for any indication, and melanoma risk. A positive association was found for higher doses of immunosuppressants. The study particularly supports drugs prescribed to OTRs, as an important risk factor for melanoma, and a positive association was also found for methotrexate. Use of corticosteroids seems not to increase the risk of melanoma. Our findings suggest that users of immunosuppressant drug types comprise a notable risk group for melanoma, and so should in addition to regular skin checkups, pursue a more cautious approach to sun exposure.

\section{Abbreviations}

All are defined in full at their first instance in the text: ATC, anatomical therapeutic chemical; CI, confidence interval; CRN, Cancer Registry of Norway; DDD, defined daily doses; ICD-O-3, International Classification of Diseases of Oncology 3rd edition; ICD-10, International Classification of Diseases 10th Revision; NM, nodular melanoma; NorPD, Norwegian Prescription Database; OTR, organ transplant recipient; PIN, personal identification number; RR, rate ratio; SSM, superficial spreading melanoma; UVR, ultraviolet radiation.

\section{Data Sharing Statement}

The data are available as presented in the paper. According to Norwegian legislation, our approvals to use the data for the current study do not allow us to distribute or make the data directly available to other parties.

\section{Ethics Approval}

The study is approved by the Norwegian Data Protection Authority and the Regional Committee for Medical and Health Research Ethics. The study is also approved by the national registries contributing with data; $\mathrm{CRN}$, the National Registry, NorPD and the Medical Birth Registry. The linkage key for the 11-digit PINs was stored and governed by a third party unavailable to the research team. All data management and analyses were conducted on data with no individual person identified. This case-control study utilized only data from nationwide population-based registers and thus did not include a recruitment process for patients, who were not involved in either the design or conduct of the study. Thus, the research question and outcome measures were not informed by any specific patient priorities, experiences or preferences. Rather, their formulation was based upon our own priorities for patient benefit and result interpretation. All results are distributed on a group level, without any possibilities for individual identification.

\section{Author Contributions}

All authors made a significant contribution to the work reported, whether that is in the conception, study design, execution, acquisition of data, analysis and interpretation, or in all these areas; took part in drafting, revising or critically reviewing the article; gave final approval of the version to be published; have agreed on the journal to which the article has been submitted; and agree to be accountable for all aspects of the work. 


\section{Funding}

The study is funded by the South-Eastern Norway Regional Health Authority (no. 16/00451-33).

\section{Disclosure}

Øystein Karlstad participates in two Post-Authorization Safety Studies (PASS) unrelated to the submitted work. The studies are on an antidiabetic drug and an anti-psoriasis drug and have been imposed by the European Medicines Agency (EMA). The studies are funded by the marketing authorization holders (Novo Nordisk and Leo Pharma) and are conducted according to the EnCePP Code of Conduct for scientific independence and transparency. The authors report no other potential conflicts of interest related to this work.

\section{References}

1. Cancer Registry of Norway. Cancer in Norway 2018 - Cancer Incidence, Mortality, Survival and Prevalence in Norway. Oslo: Cancer Registry of Norway; 2019.

2. Karimkhani C, Green AC, Nijsten T, et al. The global burden of melanoma: results from the global burden of disease study 2015. $\mathrm{Br}$ J Dermatol. 2017;177(1):134-140. doi:10.1111/bjd.15510

3. Arnold M, de Vries E, Whiteman DC, et al. Global burden of cutaneous melanoma attributable to ultraviolet radiation in 2012 Int $J$ Cancer. 2018;143(6):1305-1314. doi:10.1002/ijc.31527

4. Berwick M, Buller DB, Cust A, et al. Melanoma epidemiology and prevention. In: Kaufman HL, Mehnert JM, editors. Melanoma. Cham: Springer International Publishing; 2016:17-49.

5. Robsahm TE, Karagas MR, Rees JR, Syse A. New malignancies after squamous cell carcinoma and melanomas: a population-based study from Norway. BMC Cancer. 2014;14(1):210. doi:10.1186/1471-2407-14-210

6. Hemminki K, Zhang H, Czene K. Familial and attributable risks in cutaneous melanoma: effects of proband and age. J Clin Investig Dermatol. 2003;120(2):217-223.

7. Stenehjem JS, Veierod MB, Nilsen LT, et al. Anthropometric factors and cutaneous melanoma: prospective data from the population-based janus cohort. Int J Cancer. 2018;142(4):681-690. doi:10.1002/ijc.31086

8. De Giorgi V, Gori A, Savarese I, et al. Role of BMI and hormone therapy in melanoma risk: a case-control study. J Cancer Res Clin Oncol. 2017;143(7):1191-1197. doi:10.1007/s00432-0172387-5

9. Olsen CM. Reproductive factors and risk of melanoma: still unresolved. Br J Dermatol. 2019;181(2):239. doi:10.1111/bjd.18136

10. Rota M, Pasquali E, Bellocco R, et al. Alcohol drinking and cutaneous melanoma risk: a systematic review and dose-risk metaanalysis. Br J Dermatol. 2014;170(5):1021-1028.

11. Hartono C, Muthukumar T, Suthanthiran M. Immunosuppressive drug therapy. Cold Spring Harb Perspect Med. 2013;3(9):a015487a015487. doi: $10.1101 /$ cshperspect.a015487

12. Wiseman AC. Immunosuppressive medications. Clin J Am Soc Nephrol. 2016;11(2):332-343. doi:10.2215/CJN.08570814

13. Coutinho AE, Chapman KE. The anti-inflammatory and immunosuppressive effects of glucocorticoids, recent developments and mechanistic insights. Mol Cell Endocrinol. 2011;335(1):2-13. doi:10.1016/j. mce.2010.04.005

14. Gjersvik P. Why is the high risk of skin cancer in organ transplant recipients declining? $\mathrm{Br} \quad J$ Dermatol. 2019;181(5):879-880. doi:10.1111/bjd.18432
15. Passarelli A, Mannavola F, Stucci LS, Tucci M, Silvestris F. Immune system and melanoma biology: a balance between immunosurveillance and immune escape. Oncotarget. 2017;8(62):106132-106142. doi:10.18632/oncotarget.22190

16. Fattouh K, Ducroux E, Decullier E, et al. Increasing incidence of melanoma after solid organ transplantation: a retrospective epidemiological study. Transpl Int. 2017;30(11):1172-1180. doi:10.1111/ tri. 13011

17. Garrett GL, Blanc PD, Boscardin J, et al. Incidence of and risk factors for skin cancer in organ transplant recipients in the United States. JAMA Dermatol. 2017;153(3):296-303. doi:10.1001/jamadermatol.2016.4920

18. Green AC, Olsen CM. Increased risk of melanoma in organ transplant recipients: systematic review and meta-analysis of cohort studies. Acta Derm Venereol. 2015;95(8):923-927. doi:10.2340/00015555-2148

19. Vajdic CM, van Leeuwen MT, Webster AC, et al. Cutaneous melanoma is related to immune suppression in kidney transplant recipients. Cancer Epidemiol Biomarkers Prev. 2009;18 (8):2297-2303. doi:10.1158/1055-9965.EPI-09-0278

20. Muellenhoff MW, Koo JY. Cyclosporine and skin cancer: an international dermatologic perspective over 25 years of experience. A comprehensive review and pursuit to define safe use of cyclosporine in dermatology. J Dermatolog Treat. 2012;23(4):290-304.

21. Buchbinder R, Barber M, Heuzenroeder L, et al. Incidence of melanoma and other malignancies among rheumatoid arthritis patients treated with methotrexate. Arthritis Care Res. 2008;59(6):794-799. doi:10.1002/art.23716

22. Polesie S, Gillstedt M, Paoli J, Osmancevic A. Methotrexate and melanoma-specific mortality. J Eur Acad Dermatol Venereol. 2019;33(3):e123-e125. doi:10.1111/jdv.15305

23. Polesie S, Gillstedt M, Sonnergren HH, Osmancevic A, Paoli J. Methotrexate treatment and risk for cutaneous malignant melanoma: a retrospective comparative registry-based cohort study. $\mathrm{Br}$ J Dermatol. 2017;176(6):1492-1499. doi:10.1111/bjd.15170

24. Polesie S, Gillstedt M, Paoli J, Osmancevic A. Methotrexate exposure and risk of cutaneous malignant melanoma: no evidence of a dose-response relationship. Acta Derm Venereol. 2018;98 (9):888-895. doi:10.2340/00015555-2987

25. Ehmann LM, Tillack-Schreiber C, Brand S, Wollenberg A. Malignant melanoma during ustekinumab therapy of Crohn's disease. Inflamm Bowel Dis. 2011;18(1):E199-E200. doi:10.1002/ibd.21877

26. Nardone B, Hammel JA, Raisch DW, Weaver LL, Schneider D, West DP. Melanoma associated with tumour necrosis factor-alpha inhibitors: a research on adverse drug events and reports (RADAR) project. Br J Dermatol. 2014;170(5):1170-1172. doi:10.1111/bjd.12779

27. Esse S, Mason KJ, Green AC, Warren RB. Melanoma risk in patients treated with biologic therapy for common inflammatory diseases: a systematic review and meta-analysis. JAMA Dermatol. 2020;156 (7):787. doi:10.1001/jamadermatol.2020.1300

28. O'Donovan P, Perrett CM, Zhang X, et al. Azathioprine and UVA light generate mutagenic oxidative DNA damage. Science. 2005;309 (5742):1871-1874. doi:10.1126/science.1114233

29. Robbins HA, Clarke CA, Arron ST, et al. Melanoma risk and survival among organ transplant recipients. J Clin Investig Dermatol. 2015;135(11):2657-2665

30. Karagas MR, Cushing GL Jr., Greenberg ER, Mott LA, Spencer SK, Nierenberg DW. Non-melanoma skin cancers and glucocorticoid therapy. Br J Cancer. 2001;85(5):683-686. doi:10.1054/bjoc.2001.1931

31. Sørensen HT, Mellemkjær L, Nielsen GL, et al. Non-hodgkin lymphoma among users of systemic glucocorticoids: a population-based cohort study. J Natl Cancer Inst. 2004;96(9):709-711. doi:10.1093/jnci/djh118

32. Tseng HW, Huang WC, Lu LY. The influence of immunosuppressants on the non-melanoma skin cancer among patients with systemic lupus erythematosus and primary Sjogren's syndrome: a nationwide retrospective case-control study in Taiwan. Clin Exp Rheumatol. 2019;37(6):946-952. 
33. Castellsague J, Kuiper JG, Pottegard A, et al. A cohort study on the risk of lymphoma and skin cancer in users of topical tacrolimus, pimecrolimus, and corticosteroids (Joint European longitudinal lymphoma and skin cancer evaluation - JOELLE study). Clin Epidemiol. 2018;10:299-310. doi:10.2147/CLEP.S146442

34. Dobos J, Kenessey I, Tímár J, Ladányi A. Glucocorticoid receptor expression and antiproliferative effect of dexamethasone on human melanoma cells. Pathol Oncol Res. 2011;17(3):729-734. doi:10.1007/s12253-011-9377-8

35. Bhakoo HS, Paolini NS, Milholland RJ, Lopez RE, Rosen F. Glucocorticoid receptors and the effect of glucocorticoids on the growth of B16 melanoma. Cancer Res. 1981;41(5):1695-1701.

36. Berge LAM, Andreassen BK, Stenehjem JS, et al. Cardiovascular, antidepressant and immunosuppressive drug use in relation to risk of cutaneous melanoma: a protocol for a prospective case-control study. BMJ Open. 2019;9(2):e025246. doi:10.1136/bmjopen-2018-025246

37. Larsen IK, Smastuen M, Johannesen TB, et al. Data quality at the cancer registry of Norway: an overview of comparability, completeness, validity and timeliness. Eur $J$ Cancer Prev. 2009;45 (7):1218-1231. doi:10.1016/j.ejca.2008.10.037

38. Furu K, Wettermark B, Andersen M, Martikainen JE, Almarsdottir AB, Sorensen HT. The nordic countries as a cohort for pharmacoepidemiological research. Basic Clin Pharmacol Toxicol. 2010;106(2):86-94. doi:10.1111/j.1742-7843.2009.00494.x

39. WHO. Guidelines for ATC Classification and DDD Assignment 2015. Norwegian Institute of Public Health; 2016.

40. WHO. Collaborating centre for drug statistics methodology. Norwegian Institute of Public Health. Available from: https://www. whocc.no/. Accessed June 11, 2020.

41. Pottegård A, Friis S, Christensen R, Habel LA, Gagne JJ, Hallas J. Identification of associations between prescribed medications and cancer: a nationwide screening study. EBioMedicine. 2016;7:73-79. doi:10.1016/j.ebiom.2016.03.018

42. Felleskatalogen [Internett]. Oslo: Felleskatalogen AS. ATC-register, Antineoplastiske og immunomodulerende midler; 2020. Available from: https://www.felleskatalogen.no/medisin/atc-register/L04A. Accessed March 26, 2020.

43. Jensen AØ, Thomsen HF, Engebjerg MC, Olesen AB, Sørensen HT, Karagas MR. Use of photosensitising diuretics and risk of skin cancer: a population-based case-control study. $\mathrm{Br} J$ Cancer. 2008;99(9):1522-1528. doi:10.1038/sj.bjc.6604686

44. Monteiro AF, Rato M, Martins C. Drug-induced photosensitivity: photoallergic and phototoxic reactions. Clin Dermatol. 2016;34 (5):571-581. doi:10.1016/j.clindermatol.2016.05.006

45. Pottegard A, Friis S, Sturmer T, Hallas J, Bahmanyar S. Considerations for pharmacoepidemiological studies of drug-cancer associations. Basic Clin Pharmacol Toxicol. 2017.

46. Selvag E. Drugs and sun. Tidsskr nor Laegeforen. 2003;123 (13-14):1860-1861.

47. Berge LAM, Andreassen BK, Stenehjem JS, et al. Use of antidepressants and risk of cutaneous melanoma: a prospective registry-based case-control study. Clin Epidemiol. 2020;12:193-202. doi:10.2147/ CLEP.S241249

48. Medhaug I, Olseth JA, Reuder J. UV radiation and skin cancer in Norway. J Photochem Photobiol B. 2009;96(3):232-241. doi:10. 1016/j.jphotobiol.2009.06.011

49. Robsahm TE, Tretli S. Cutaneous malignant melanoma in Norway: variation by region of residence before and after the age 17. Cancer Causes Control. 2001;12(6):569-576. doi:10.1023/A:1011287918405

50. Gandini S, Iodice S, Koomen E, Di Pietro A, Sera F, Caini S. Hormonal and reproductive factors in relation to melanoma in women: current review and meta-analysis. Eur J Cancer. 2011;47 (17):2607-2617. doi:10.1016/j.ejca.2011.04.023
51. Karagas MR, Zens MS, Stukel TA, et al. Pregnancy history and incidence of melanoma in women: a pooled analysis. Cancer Causes Control. 2006;17(1):11-19. doi:10.1007/s10552-005-0281-y

52. Pearce N. What does the odds ratio estimate in a case-control study? Int J Epidemiol. 1993;22(6):1189-1192. doi:10.1093/ije/22.6.1189

53. Wang M, Spiegelman D, Kuchiba A, et al. Statistical methods for studying disease subtype heterogeneity. Stat Med. 2016;35 (5):782-800. doi:10.1002/sim.6793

54. R: A language and environment for statistical computing. [computer program]. Vienna, Austria: R Foundation for Statistical Computing; 2018.

55. Ciechomska I, Legat M, Golab J, et al. Cyclosporine A and its non-immunosuppressive derivative NIM811 induce apoptosis of malignant melanoma cells in in vitro and in vivo studies. Int J Cancer. 2005;117(1):59-67. doi:10.1002/ijc.21153

56. Nihal M, Wu J, Wood GS. Methotrexate inhibits the viability of human melanoma cell lines and enhances Fas/Fas-ligand expression, apoptosis and response to interferon-alpha: rationale for its use in combination therapy. Arch Biochem Biophys. 2014;563:101-107. doi:10.1016/j.abb.2014.04.019

57. Romano MF, Avellino R, Petrella A, Bisogni R, Romano S, Venuta S. Rapamycin inhibits doxorubicin-induced NF- $\mathrm{KB} /$ Rel nuclear activity and enhances the apoptosis of melanoma cells. Eur $J$ Cancer. 2004;40(18):2829-2836. doi:10.1016/j.ejca.2004.08.017

58. Rizvi SMH, Aagnes B, Holdaas H, et al. Long-term change in the risk of skin cancer after organ transplantation: a population-based nationwide cohort study. JAMA Dermatol. 2017;153(12):1270-1277. doi:10.1001/jamadermatol.2017.2984

59. Mérot Y, Miescher PA, Balsiger F, Magnenat P, Frenk E. Cutaneous malignant melanomas occurring under cyclosporin A therapy: a report of two cases. $\mathrm{Br} J$ Dermatol. 1990;123(2):237-239. doi:10.1111/j.1365-2133.1990.tb01852.x

60. Pedersen EG, Pottegard A, Hallas J, et al. Risk of non-melanoma skin cancer in myasthenia patients treated with azathioprine. Eur J Neurol. 2014;21(3):454-458. doi:10.1111/ene.12329

61. Kerensky TA, Gottlieb AB, Yaniv S, Au S-C. Etanercept: efficacy and safety for approved indications. Expert Opin Drug Saf. 2012;11 (1):121-139. doi:10.1517/14740338.2012.633509

62. Lebwohl M, Blum R, Berkowitz E, et al. No evidence for increased risk of cutaneous squamous cell carcinoma in patients with rheumatoid arthritis receiving etanercept for up to 5 years. Arch Dermatol. 2005;141(7):861-864. doi:10.1001/archderm.141.7.861

63. Mercer LK, Askling J, Raaschou P, et al. Risk of invasive melanoma in patients with rheumatoid arthritis treated with biologics: results from a collaborative project of 11 European biologic registers. Ann Rheum Dis. 2017;76(2):386-391. doi:10.1136/annrheumdis-2016209285

64. Banciu M, Schiffelers RM, Fens MHAM, Metselaar JM, Storm G. Anti-angiogenic effects of liposomal prednisolone phosphate on B16 melanoma in mice. J Control Release. 2006;113(1):1-8. doi:10.1016/ j.jconrel.2006.03.019

65. DiSorbo DM, McNulty B, Nathanson L. Growth inhibition of human malignant melanoma cells by glucocorticoids. Cancer Res. 1983;43 (6):2664-2667.

66. Yano A, Fujii Y, Iwai A, Kageyama Y, Kihara K. Glucocorticoids suppress tumor angiogenesis and in vivo growth of prostate cancer cells. Clin Cancer Res. 2006;12(10):3003-3009. doi:10.1158/10780432.CCR-05-2085

67. Herings RMC, Pedersen L. Pharmacy-based medical record linkage systems. In: Strom BL, Kimmel SE, Hennessy S, editors. Pharmacoepidemiology. 2012:270-286.

68. Matas AJ. What's new and what's hot in transplantation: clinical science ATC 2003. Am J Transplant. 2003;3(12):1465-1473. doi:10.1046/j.1600-6135.2003.00285.x 
69. Maiorino A, De Simone C, Perino F, Caldarola G, Peris K Melanoma and non-melanoma skin cancer in psoriatic patients treated with high-dose phototherapy. J Dermatolog Treat. 2016;27 (5):443-447. doi:10.3109/09546634.2015.1133882
70. NorPD. Statistics from the Norwegian prescription database. Norwegian Institute of Public Health; 2020. Available from: http:// norpd.no/Prevalens.aspx. Accessed August 19, 2020.

\section{Publish your work in this journal}

Clinical Epidemiology is an international, peer-reviewed, open access, online journal focusing on disease and drug epidemiology, identification of risk factors and screening procedures to develop optimal preventative initiatives and programs. Specific topics include: diagnosis, prognosis, treatment, screening, prevention, risk factor modification,

Submit your manuscript here: https://www.dovepress.com/clinical-epidemiology-journal systematic reviews, risk \& safety of medical interventions, epidemiology \& biostatistical methods, and evaluation of guidelines, translational medicine, health policies \& economic evaluations. The manuscript management system is completely online and includes a very quick and fair peer-review system, which is all easy to use. 